\section{Injectable local anaesthetic for IUD/IUS fittings}

I am responding to the letter from Sam Hutt that appeared in the January 2011 issue of the Journal. ${ }^{1}$ I am aware of Dr Hutt's strong feelings about the use of local anaesthesia during intrauterine device (IUD) fitting. He lectures on the Margaret Pyke theoretical course for nurses, and when I start their practical training it is the aspect about which they are often most anxious. When I say that I do not use local anaesthetic when fitting IUDs they heave a sigh of relief. Dr Hutt says that it is simple, safe and painless to administer. I would disagree. I work in colposcopy clinics and give many local infiltrations of local anaesthetic into the cervix. It can be quite uncomfortable but of course is necessary if one is going to perform a loop excision. It does not prevent internal os spasm or pain; for that one would need to give a paracervical block. It is fairly simple to give the injection in the clinic where the patient is in the lithotomy position and the lighting is excellent; it is not so easy in most general practices. If one uses lignocaine with adrenalin there is not uncommonly some palpitation, which can be unpleasant. Many patients are more worried about the injection than they are about the subsequent procedure.

I have spoken to many of my general practitioner friends who fit IUDs and none of them gives local anaesthetic before insertion. I have also spoken to the nurse hysteroscopist at the hospital who is performing cervical dilatation very often on postmenopausal women whom one would anticipate would have greater problems with cervical dilatation. She never uses local anaesthetic.

I have worked for years in general practice and very often get patients coming requesting an intrauterine system (IUS) because they have friends who recommend it. That is certainly not restricted to those who have had a local anaesthetic. Dr Hutt paints a picture I do not recognise of patients collapsing, experiencing unpleasant and avoidable vasovagal attacks. He quotes his personal rate of $4 \%$ having some sort of problem. I should think that my experience without local anaesthetic would be certainly no higher than that! It is very unusual to have a patient collapsing after insertion and most of them go back to their normal activity straight away. The extreme and overwhelming pain he describes simply does not happen to most women. I usually suggest that they take an analgesic or non-steroidal anti-inflammatory drug (NSAID) before coming to the surgery, although I am aware that there is no evidence base for this.

It is interesting that the Clinical Effectiveness Unit (CEU) of the Faculty of Sexual and Reproductive Healthcare (FSRH) guidance on intrauterine contraception contains only one line on local anaesthesia. ${ }^{2}$ If less than $5 \%$ of the doctors he surveyed are using injectable local anaesthesia for IUD/IUS fittings, perhaps it is Sam Hutt who is out of step.

\section{Beth Devonald, MRCGP, DFSRH}

Associate Specialist, Lincoln County Hospital, Women \& Children, Coleby, Lincoln, UK: devonald@btinternet.com

Competing interests None.

J Fam Plann Reprod Health Care 2011;37:119. doi:10.1136/fprhc.2011.0095

\section{REFERENCES}

1 Hutt S. Injectable local anaesthetic for IUD/IUS fittings [Letter]. J Fam Plann Reprod Health Care 2011;37:59

2 Faculty of Sexual and Reproductive Healthcare Clinical Guidance. Intrauterine Contraception. 2007. http://www.fsrh.org/admin/uploads/ CEUGuidancelntrauterineContraceptionNov07.pdf (accessed 26 February 2011). 